\title{
Contact tracing of COVID-19 infections in Lubbock County in West Texas
}

\author{
Madeline McClure Geeslin MPH, Katherine Wells, MPH
}

The accompanying illustration represents the first approximately 2,000 cases of Covid-19 in Lubbock County, Texas. Through contact tracing, we were able to connect cases to one another, and we were often able to determine the origin of the outbreak in each cluster. Many of the clusters represent nursing homes, where the virus was brought in by staff and then spread through the facility. In one such cluster, we were able to identify a nursing home employee who attended a family gathering, which ultimately resulted in 38 cases, both in the nursing home and from those at the gathering (including at least one other healthcare worker). Another large cluster represents an outbreak connected to a local bar. When we identified this location as a hot spot, we went to the bar and tested all of the staff. More than $50 \%$ tested positive during this pointin-time screening. The bar was subsequently closed for two weeks and then closed in accordance with Governor Greg Abbott's orders. Close inspection of the diagram reveals individuals who appear to be particularly infectious, perhaps as a result of an asymptomatic or mildly symptomatic infection or high viral load. For whatever reason, several people proved to be very effective hosts and vectors of disease transmission.

This was a helpful schematic during the early stages of the novel pandemic; however, as the outbreak in our community progressed, people began to be less cooperative, so contact tracing became less helpful in identifying clusters. Even without the full cooperation of individuals, through this platform we were able to connect some cases that might otherwise have gone unnoticed, such as a cluster of cases

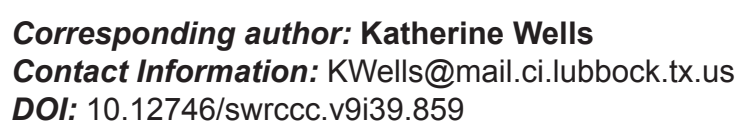

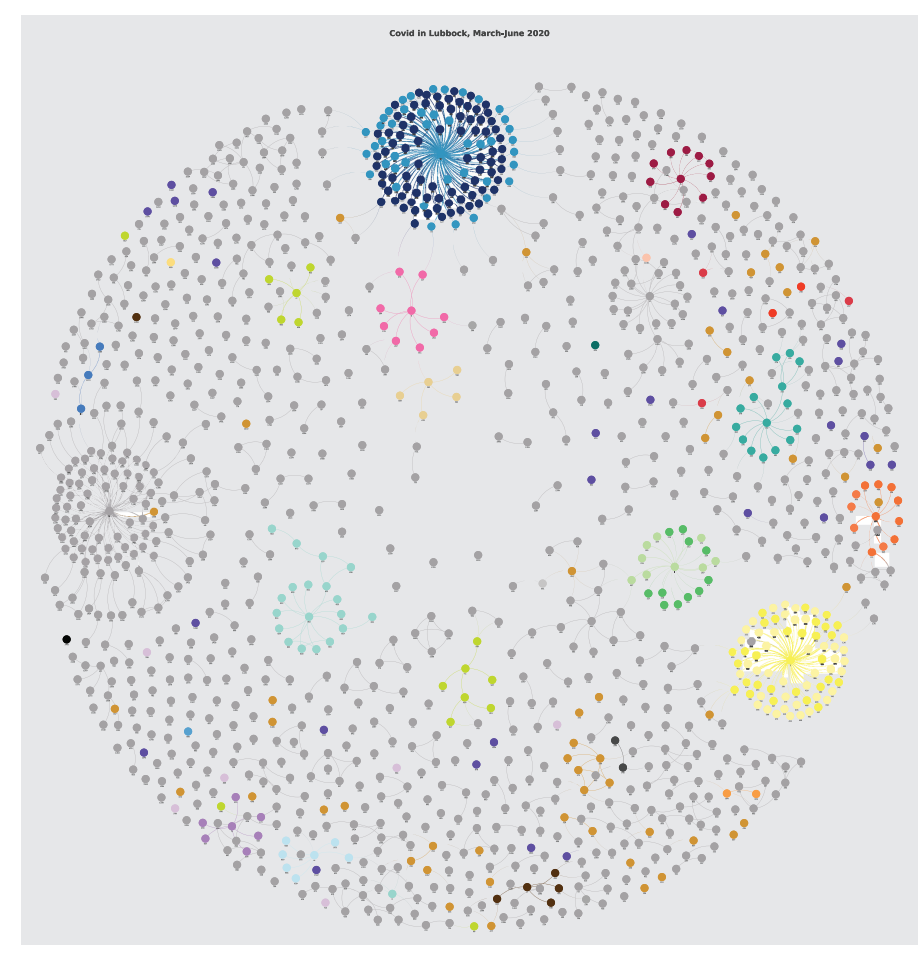

of juveniles who were all in attendance at a funeral and at the "kickback" that followed.

Keywords: contact tracing, COVID-19, clusters, "hot spots"

Article citation: Geeslin MM, Wells K. Contact tracing of COVID-19 infections in Lubbock County in West Texas. The Southwest Respiratory and Critical Care Chronicles 2021;9(39):85

From: City of Lubbock Health Department, Lubbock, Texas

Submitted: $4 / 8 / 2021$

Accepted: 4/8/2021

Conflicts of interest: none

This work is licensed under a Creative Commons Attribution-ShareAlike 4.0 International License. 